\title{
Genetic structure and diversity of a rare woodland bat, Myotis bechsteinii: comparison of continental Europe and Britain
}

\author{
Patrick G. R. Wright ${ }^{1}$ (I) - Patrick B. Hamilton ${ }^{1}$ (C) - Henry Schofield ${ }^{2} \cdot$ Anita Glover $^{2} \cdot$ Christopher Damant $^{3}$. \\ Ian Davidson-Watts ${ }^{4}$ Fiona Mathews ${ }^{1,5}$
}

Received: 7 September 2017 / Accepted: 7 February 2018 / Published online: 13 February 2018

(c) The Author(s) 2018. This article is an open access publication

\begin{abstract}
The Bechstein's bat (Myotis bechsteinii) is a rare sedentary bat considered to be highly reliant on the presence of ancient woodland. Understanding the genetic connectivity and population structure of such elusive mammals is important for assessing their conservation status. In this study, we report the genetic diversity and structure of $M$. bechsteinii across Britain and Europe. Assessments were made using 14 microsatellite markers and a $747 \mathrm{bp}$ region of the mitochondrial cytochrome $\mathrm{b}$ gene. Nuclear DNA (microsatellites) showed high levels of genetic diversity and little inbreeding across the species range, though genetic diversity was slightly lower in Britain than in mainland Europe. Bayesian and spatial PCA analysis showed a clear separation between the British and European sites. Within Europe, the Italian population south of the Alps was isolated from the other sites. In Britain, there was genetic structuring between the northern and southern part of the geographical range. Despite there being little genetic divergence in mitochondrial DNA (mtDNA) sequences throughout most of Europe, the mtDNA patterns in Britain confirmed this separation of northern and southern populations. Such genetic structuring within Britain—in the absence of any obvious physical barriers—suggests that other factors such as land-use may limit gene-flow.
\end{abstract}

Keywords Chiroptera $\cdot$ Cytochrome $\mathrm{b} \cdot$ Mammal conservation $\cdot$ Conservation genetics $\cdot$ Habitat fragmentation $\cdot$ Gene flow

\section{Introduction}

The fitness and viability of populations, along with their ability to adapt to environmental change, are strongly influenced by genetic diversity (Reed and Frankham 2003). In Europe, urbanisation and industrial agriculture have significantly increased during the twentieth century leading to further habitat loss and fragmentation (Baker and Harris

Electronic supplementary material The online version of this article (https://doi.org/10.1007/s10592-018-1053-z) contains supplementary material, which is available to authorized users.

Fiona Mathews

F.mathews@sussex.ac.uk

1 Bioscience, College of Life and Environmental Sciences, University of Exeter, Exeter, UK

2 The Vincent Wildlife Trust, Ledbury, Herefordshire, UK

3 Bernwood ECS Ltd, Swanbourne, Buckinghamshire, UK

4 Davidson-Watts Ecology Ltd, Salisbury, Wiltshire, UK

5 Present Address: College of Life Sciences, University of Sussex, Falmer, UK
2007). These practices have resulted in a sharp decline of mammal, bird, amphibian and invertebrate populations across a diverse array of habitats (e.g. Marzluff 2001; Potts et al. 2010) and have contributed towards the loss of genetic diversity and increased differentiation in protected species, such as Lutra lutra (Stanton et al. 2009), Rhinolophus ferrumequinum (Rossiter et al. 2000) and Bombus sylvarum (Ellis et al. 2006).

Despite their abundance and functional importance to ecosystems, very limited information is available on the biology and conservation status of most bat species. Being small, nocturnal and highly vagile, bats are particularly hard to study directly (O'Shea and Bogan 2003; Puechmaille et al. 2007). However, the use of molecular techniques has provided valuable information on a number of species by contributing towards a better understanding of mating behaviour (Bryja et al. 2009), social behaviour (Kerth et al. 2000) and other aspects of the biology. The high mobility of bats compared with other terrestrial mammals along with behaviours, such as migration (Ahlén et al. 2009; Bryja et al. 2009) and autumnal swarming (Glover and Altringham 2008; Kerth 
et al. 2003; McDevitt et al. 2009; Moussy et al. 2013; Parsons and Jones 2003), has allowed them to maintain high levels of gene flow and little genetic differentiation throughout their range despite environmental pressures and changes in land management (Ibáñez et al. 2006). The consequence of these pressures is, however, more likely to be apparent in Britain than mainland Europe since populations on highly inhabited islands are more susceptible to genetic drift and inbreeding which can subsequently lead to extinction (Frankham 1997).

The Bechstein's bat (Myotis bechsteinii) is a woodland specialist, widespread throughout central and western Europe; ranging from the Iberian Peninsula, to southern Scandinavia and the Caucasus (Dietz and Pir 2011; Vergari et al. 1998). Its current distribution, however, is highly insular, and is influenced by the presence of old growth oak and beech woodland. In Britain, post-glacial fossil deposits suggest that it was once more widespread, but that forest clearance during the Neolithic phase might have restricted their distribution to southern Britain (Yalden 1992, 1999). The species roosts predominantly in tree holes, particularly those made by woodpeckers, and whilst males are solitary, females breed in maternity groups which are thought to be closed. Foraging usually occurs within $3 \mathrm{~km}$ from day roosts, and whilst roost switching is common, the species is highly sedentary (Dietz and Pir 2011). M. bechsteinii is classified as Near Threatened (Paunović 2016) and "in need of strict protection" by the European Habitats Directive (92/43/CEE). Autumn swarming plays a key role in maintaining low genetic differentiation in M. bechsteinii (Kerth et al. 2003), but the isolation of essential mating sites may have resulted in a loss of genetic diversity (Durrant et al. 2009). Climate change is expected to impact the distribution of many species (Razgour et al. 2017; Rebelo et al. 2010), and it is therefore important to understand the interactions between the British and continental populations of $M$. bechsteinii. Yet current knowledge is mostly restricted to continental studies (e.g. Kerth et al. 2008) whilst information on the British population remains limited to coastal populations (Durrant et al. 2009).

In this study, we used 14 microsatellites and a $747 \mathrm{bp}$ fragment of the cytochrome $b$ gene (mtDNA) to investigate the genetic diversity and structure of $M$. bechsteinii in Britain in comparison with the continental population. We hypothesised that the British population would show significant differentiation from the continental population. We also predicted that the British population would show lower levels of genetic diversity and more structure than their European counterparts given that this population is an edge of range population isolated from the rest of Europe where suitable habitat is sparser.

\section{Materials and methods}

\section{Sample collection}

A total of 328 individuals from 15 sites were included in this study. All British sites were unique maternity colonies with the exception of the Bernwood population which comprised three maternity colonies within a $3 \mathrm{~km}$ radius, and all samples from the Isle of Wight were grouped into one population (Fig. 1). Samples in Britain were collected during woodland surveys and those from continental Europe were collected at swarming sites. As $M$. bechsteinii rarely travel over $30 \mathrm{~km}$ to reach swarming sites (Dekeukeleire et al. 2016), it was judged that at a continental scale, where study sites are separated by over $100 \mathrm{~km}$, swarming sites would be representative of the sampled area since individuals are likely to originate from a nearby population. A wing tissue sample was taken from each bat using a $3 \mathrm{~mm}$ biopsy punch (Stiefel Laboratories, Wooburn Green, UK) and stored in absolute ethanol at $-4{ }^{\circ} \mathrm{C}$ until DNA extraction. In addition, 9 bat droppings were also directly collected from individual bats to provide additional information on the Bernwood population. All bats were described (sex, age and other biometric measurements) and released within a few minutes of the procedure at their location of capture. Sampling was conducted under licence from the Home Office (ref no PPL 3003431) and Natural England (2016-24055-SCI-SCI) and was approved by the Ethics Committee of the College of Life Sciences, University of Exeter.

\section{DNA extraction, PCR and microsatellite genotyping}

DNA was extracted from each wing biopsy with DNeasy blood \& tissue kits (QIAGEN). Samples were then incubated twice for $5 \mathrm{~min}$ in 80 and $40 \mu \mathrm{l}$ of buffer AE to form a final solution of $120 \mu \mathrm{l}$. DNA extraction from bat droppings was performed using a QIAmp DNA Stool Mini Kit (QIAGEN) following the protocol recommended by Puechmaille et al. (2007). PCR was carried out in $10 \mu \mathrm{l}$ volume reactions containing $5 \mu$ of Type-it Microsatellite PCR Kit (QIAGEN), $2 \mu$ of RNAse free water, $1 \mu \mathrm{l}$ of extracted DNA and $2 \mu \mathrm{l}$ of primer mixture (Table S1).

A set of 14 microsatellite loci primarily designed for the study of other bat species were selected for genotyping M. bechsteinii. A touchdown extra-long PCR program was used, consisting of $5 \mathrm{~min}$ at $95 \mathrm{C}$ followed by 35 cycles of $30 \mathrm{~s}$ at $95{ }^{\circ} \mathrm{C}, 90 \mathrm{~s}$ at the annealing temperature $\left[62{ }^{\circ} \mathrm{C}\right.$ (3 cycles), 58 (4), 55 (5), 53 (10), 51 (5), 49 (5), 47 (5)] and $3 \mathrm{~min}$ at $72{ }^{\circ} \mathrm{C}$, then 72 and $60{ }^{\circ} \mathrm{C}$ for 10 and $35 \mathrm{~min}$ respectively followed by a final $10 \mathrm{~min}$ extension step at 


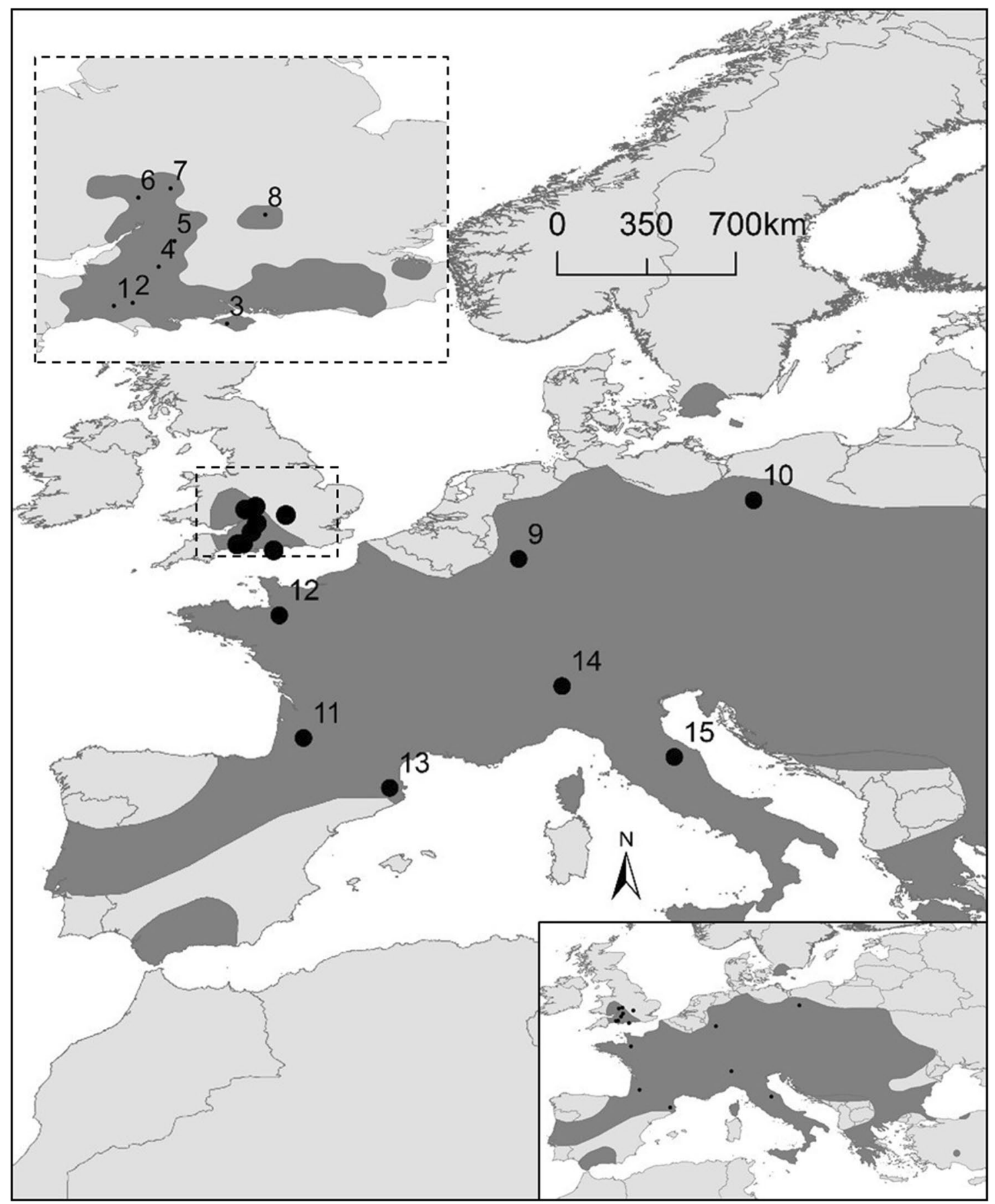

Fig. 1 Distribution map of M. bechsteinii in Britain and Europe (Couzens et al. 2017; Paunović 2016) with location of sampled sites. See Table 1 for details on population identity

$72{ }^{\circ} \mathrm{C}$. Genotyping was performed on a Beckman Coulter $\mathrm{CEQ}^{\mathrm{TM}} 8000$ Genetic Analysis System.

\section{Mitochondrial sequencing}

A portion of $860 \mathrm{bp}$ of the mtdna cytochrome $\mathrm{b}$ gene was amplified in a subset of samples using primers Molcit-F
(5'-AATGACATGAAAAATCACCGTTGT-3'), (Ibáñez et al. 2006) and MVZ-16 (5'-AAATAGGAARTATCAYTC TGGTTTRAT-3'), (Smith and Patton 1993). PCR was carried out in $20 \mu \mathrm{l}$ with $10 \mu \mathrm{l}$ Type-it Microsatellite PCR Kit, $1.5 \mu \mathrm{M}$ of each primer, and $1 \mu \mathrm{l}$ of DNA. The remaining volume was made up with RNAse-Free water. PCR conditions employed a "touchdown" PCR program consisting 
of $5 \mathrm{~min}$ at $95{ }^{\circ} \mathrm{C}$ followed by 35 cycles of $30 \mathrm{~s}$ at $95{ }^{\circ} \mathrm{C}$, $30 \mathrm{~s}$ at the annealing temperature $\left[62{ }^{\circ} \mathrm{C}(3\right.$ cycles $), 58{ }^{\circ} \mathrm{C}$ (4), 55 (5), 53 (10), 51 (5), 49 (5), 47 (5)] and $1 \mathrm{~min}$ at $72{ }^{\circ} \mathrm{C}$, then 72 and $60{ }^{\circ} \mathrm{C}$ for 10 and 35 min respectively. PCR reactions were then sent for clean-up and sequenced from both directions at SourceBioscience (UK) (https:// www.sourcebioscience.com/). The resulting sequences were assembled, aligned and trimmed into DNAbaser (DNA Sequence Assembler v4, 2013) to create a 747 bp consensus sequence for each individual. A total of five $M$. bechsteinii cytochrome b sequences obtained from Genbank (Accession KF218378.1, AF376843.1, DQ120901.1, DQ120900.1, DQ120899.1) were also included in our analysis. Accession numbers from this study are MF182931-MF183112.

\section{Data quality}

For DNA microsatellite data, the presence of scoring inconsistencies, null alleles, large allele dropout and stuttering was tested in MICROCHECKER (Van Oosterhout et al. 2004). Exact tests for departure from Hardy-Weinberg (HW) equilibrium were performed for each roost and each locus in GENEPOP 4.1.4 (Rousset 2008) under the hypothesis of heterozygote deficit. A sequential Bonferonni correction was applied to the p-values to account for multiple tests (Rice 1989). Tests of linkage disequilibrium were performed and the significance levels were adjusted by sequential Bonferonni correction.

\section{Genetic diversity}

Indices of genetic diversity, such as observed heterozygosity (Ho), expected heterozygosity (He), inbreeding coefficients $\left(\mathrm{F}_{\mathrm{IS}}\right)$, were calculated using GENALEX 6.5 (Peakall and Smouse 2012). Allelic richness (Ar) was calculated using the rarefaction method with the software HP-Rare as this method takes into account differences in sample size (Kalinowski 2005). A Monte Carlo test of 999 permutations was performed to compare differences in expected heterozygosity $(\mathrm{He})$ between Britain and mainland Europe Bechstein's bats with the R package ADEGENET (Jombart 2008).

\section{Genetic structure and isolation by distance}

Isolation by distance (IBD) was tested by Mantel test between a matrix of genetic distances (Edward's distance) and a matrix of Euclidean geographic distances. These tests were performed on the full dataset and separately on the continental and British dataset with the R package ADEGENET and Kernel density estimates were applied to the correlation plots (Jombart 2008).
Genetic differentiation was first examined by calculating the global and pair-wise Fst in genalex 6.5 (Peakall and Smouse 2012) where the significance of estimates was based on 999 permutations of the dataset. Then, to investigate genetic structure, the Bayesian clustering program STRUCTURE v 2.3.3 (Pritchard et al. 2000) was used with a burn-in period of 50000 iterations followed by 150000 iterations with the number of inferred populations $(\mathrm{K})$ ranging from 1 to 12 . We performed ten independent runs of the program using the population admixture model and correlated allele frequencies using the LOCPRIOR option. We determined the most likely number of population clusters using the $\Delta \mathrm{K}$ statistic (Evanno et al. 2005). The clusters identified were then run separately in order to identify finer levels of structure.

The R package ADEGENET (Jombart 2008) was used to further investigate spatial genetic patterns at all sites by performing a spatial principal component analysis (sPCA). This method incorporates spatial autocorrelation (Moran's $I$ ) to more commonly used PCAs in multivariate analysis. As opposed to STRUCTURE and other Bayesian approaches, sPCAs measure the contribution of all alleles within genotypes and does not assume that populations are in Hardy-Weinberg equilibrium or that there is any linkage equilibrium between loci. Different components are differentiated into global scores (positive eigenvalues) which distinguish clusters and clines from allele frequencies, whereas local scores (negative eigenvalues) detect differences between neighbouring individuals. We performed a multivariate test with a Monte Carlo procedure of 1000 permutations to test for the significance of both patterns.

\section{Mitochondrial DNA analysis}

Indices of mtDNA diversity (number of haplotypes, haplotype diversity and nucleotide diversity) and haplotype matrices were analysed with MEGA (Tamura et al. 2007). The frequency of haplotypes was plotted at all sites using the R package MAPPLOTS and a median joining network was constructed using POPART (Leigh and Bryant 2015).

\section{Results}

\section{Data quality}

Of the 14 microsatellites genotyped, evidence of homozygote excess and null alleles were detected at 6 loci (Mluc8, CA38, Mnatt6, MS3D02, H23 \& Kpa24), but none of these inconsistencies were consistently detected in different populations. None of the microsatellites analysed showed indication of linkage disequilibrium (LD) between all populations. Tests for Hardy-Weinberg equilibrium (HWE) revealed 
that eight loci showed significant deviation from HWE, but these did not differ from HWE in more than one population. All loci were retained for further analysis as they did not show persistent evidence of inconsistencies across multiple populations.

\section{Genetic diversity}

Levels of genetic diversity in Bechstein's bats were high across all sites. Allelic richness varied from 5.09 in Braydon, UK to 6.34 in Germany (Table 1). Expected heterozygosity (He) ranged from 0.739 (Bernwood, UK) to 0.809 (Lombardy) and observed heterozygosity ranged from 0.755 (Malvern, UK) to 0.886 (Lombardy). Expected heterozygosity $(\mathrm{He})$ was significantly higher in Europe (Monte-Carlo test, $\mathrm{R}$-squared $=-0.04, \mathrm{p}=0.001$ ). Levels of inbreeding were low for all sites studied with the exception of the Bernwood population $\left(\mathrm{F}_{\mathrm{IS}}=0.121\right)$.

\section{Isolation by distance and genetic structure}

The correlation between genetic and geographic distance showed significant spatial structure on the full dataset $(r=0.616, p=0.002)$ (Fig. 2a); whereas individually, the continental dataset $(r=-0.054, p=0.575)$ and the British dataset $(r=0.267, p=0.169)$ showed no such relationship (Fig. 2b, c).
Global Fst for all populations was 0.032 ( $\mathrm{p}<0.001$, Table S3). The highest Fst between all populations was between Braydon and Umbria $(F s t=0.106, p<0.001)$. The lowest Fst was between western Germany and western Poland $(\mathrm{Fst}=-0.015, \mathrm{p}=0.472)$. Almost all pairwise Fst values were statistically significant $(\mathrm{p}<0.05)$, except for those between certain continental sites (Pop 9, 10, 11, 12) and in Grafton (Pop 7).

The number of clusters calculated by STRUCTURE was $\mathrm{K}=2$ based on the $\Delta \mathrm{K}$ method (Evanno et al. 2005). At $\mathrm{K}=2$, continental sites comprised one group and all sites in Britain were included in the same group (Fig. 3a). Separate runs on both populations were performed in order to identify higher levels of structure. In Britain, a clear distinction between populations in the south of Britain and the northern part of the species range in Britain was observed (Fig. 3b). Further runs at higher K showed some differentiation between Braydon (Pop 5) and all other populations (Figure S1). On the continent, differentiation was observed between the Italian populations and the rest of our study sites (Fig. 3c).

For the sPCA, the global test indicated clear global structuring across Britain and Europe (Monte-Carlo test, $\mathrm{R}$-squared $=0.55, \mathrm{p}=0.01$ ). The representation of the first two eigenvalues confirmed the differentiation between the British and continental bats observed in the STRUCTURE analysis (Fig. 4a). The first eigenvector (Fig. 4b), which showed the largest variance and spatial autocorrelation,
Table 1 Measures of genetic diversity at all sites using 14 microsatellite loci

\begin{tabular}{llrlllr}
\hline Pop ID & Population & $\mathrm{N}$ & $\mathrm{Ar}$ & $\mathrm{He}$ & $\mathrm{Ho}$ & \multicolumn{1}{c}{$\mathrm{F}_{\mathrm{IS}}$} \\
\hline 1 & Brackett's Coppice & 68 & 5.44 & 0.777 & 0.785 & -0.009 \\
2 & Sherborne & 30 & 5.45 & 0.779 & 0.797 & -0.020 \\
3 & Isle of Wight & 40 & 5.40 & 0.771 & 0.764 & 0.010 \\
4 & Trowbridge & 40 & 5.37 & 0.769 & 0.793 & -0.030 \\
5 & Braydon & 28 & 5.09 & 0.756 & 0.765 & -0.013 \\
6 & Malvern & 30 & 5.47 & 0.775 & 0.783 & -0.009 \\
7 & Grafton & 6 & 5.57 & 0.742 & 0.798 & -0.069 \\
8 & Bernwood & 18 & 5.13 & 0.739 & 0.654 & 0.121 \\
& All samples from Britain & $\mathbf{2 6 0}$ & $\mathbf{5 . 6 5}$ & $\mathbf{0 . 7 9 6}$ & $\mathbf{0 . 7 7 3}$ & $\mathbf{0 . 0 3 0}$ \\
9 & Western Germany & 8 & 6.34 & 0.790 & 0.804 & -0.020 \\
10 & Western Poland & 10 & 5.91 & 0.776 & 0.743 & 0.041 \\
11 & Aquitaine & 10 & 6.15 & 0.791 & 0.814 & -0.031 \\
12 & Brittany & 10 & 5.67 & 0.753 & 0.821 & -0.088 \\
13 & Catalonia & 10 & 5.86 & 0.755 & 0.779 & -0.038 \\
14 & Lombardy & 10 & 6.23 & 0.806 & 0.886 & -0.099 \\
15 & Umbria & 10 & 5.57 & 0.746 & 0.793 & -0.072 \\
& All samples from Continental & $\mathbf{6 8}$ & $\mathbf{6 . 3 1}$ & $\mathbf{0 . 8 3 5}$ & $\mathbf{0 . 8 0 6}$ & $\mathbf{0 . 0 3 6}$ \\
& Europe & & & & & $\mathbf{0 . 0 3 9}$ \\
\hline & All samples & $\mathbf{3 2 8}$ & $\mathbf{5 . 8 8}$ & $\mathbf{0 . 8 1 1}$ & $\mathbf{0 . 7 8 0}$ & $\mathbf{0 . 0 3 6}$ \\
\hline
\end{tabular}

Sample size $(\mathrm{N})$, allelic richness (Ar), expected (He) and observed (Ho) heterozygosity and inbreeding coefficient $\left(\mathrm{F}_{\mathrm{IS}}\right)$. The overall results from Britain, Continental Europe and all sites are represented in bold italic 
Fig. 2 Mantel test for isolation by distance on a the full dataset; b the continental dataset; $\mathbf{c}$ the British dataset with applied Kernel density estimates to the online) correlation plots. (Color figure

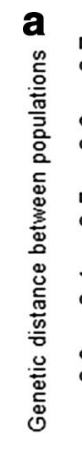
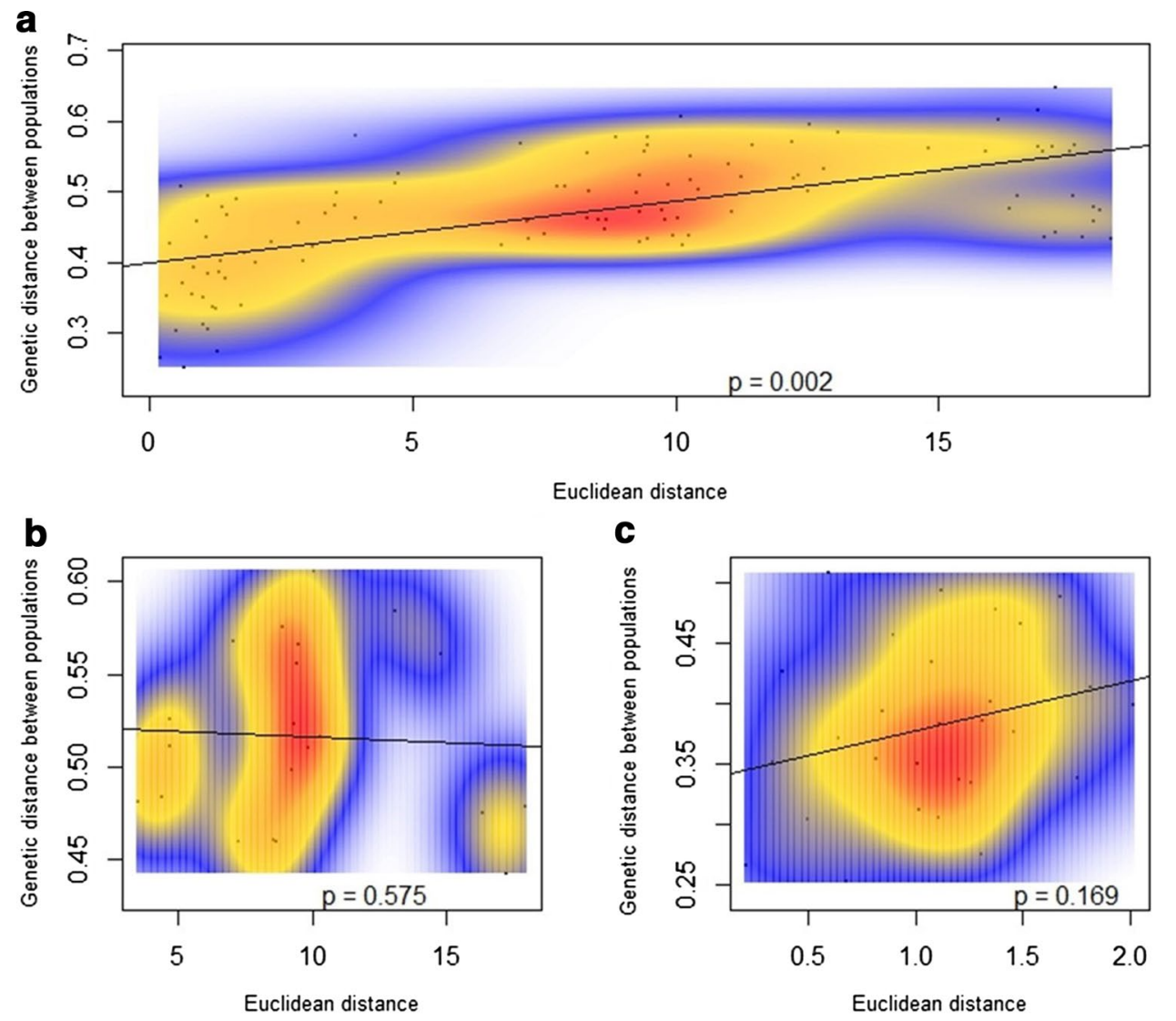

Euclidean distance

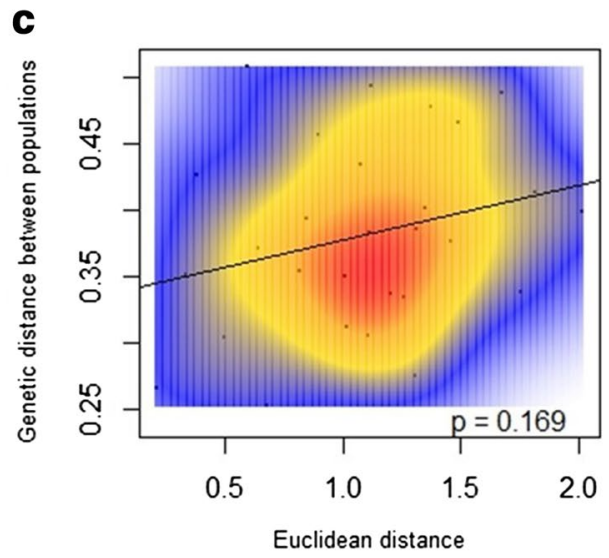

a
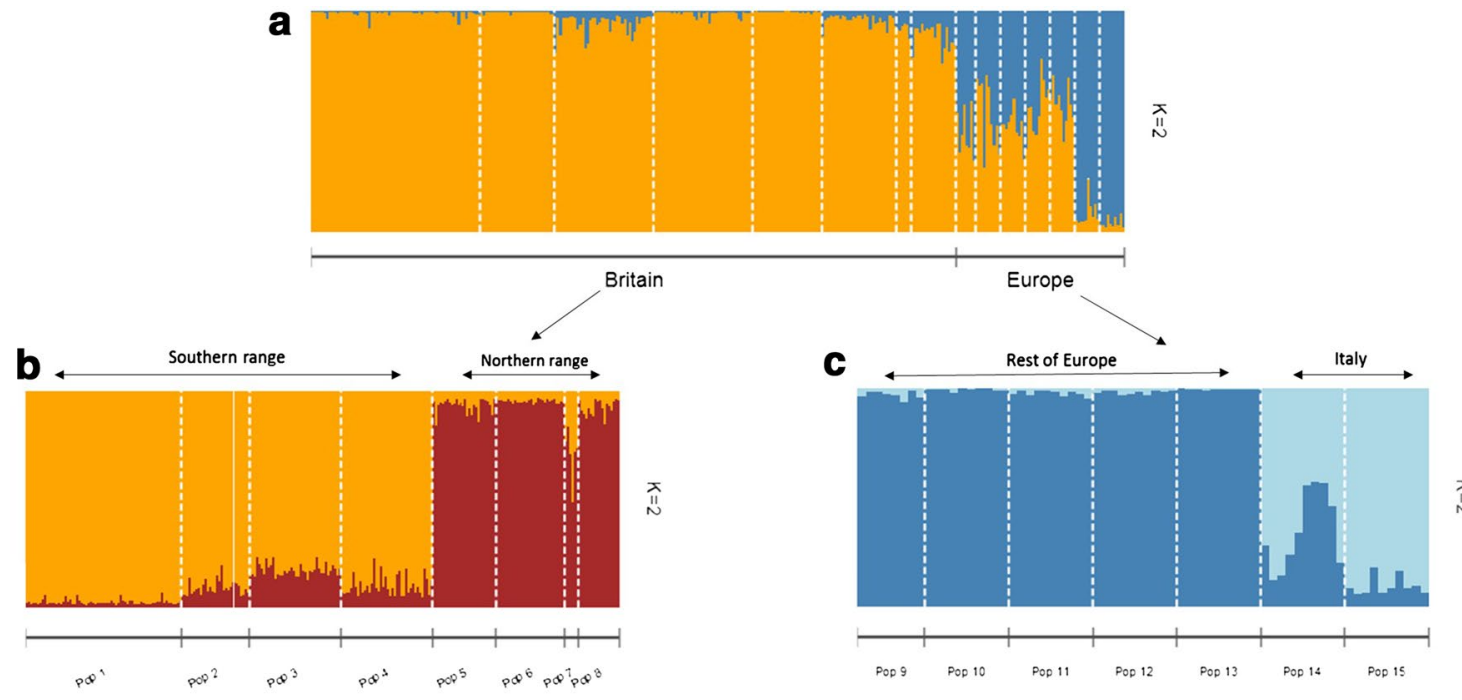

Fig. 3 Genetic structure diagram produced by STRUCTURE-a Primary structure of all populations $(K=2)$, b Independent runs of STRUCTURE in Britain (left) and c Continental populations $(\mathrm{K}=2)$. Each vertical bar represents an individual, and each colour represents the probability of belonging to one of the genetic clusters. Dashed

lines separate sites the individuals were sampled from. 1 Brackett's Coppice, 2 Sherborne, 3 Isle of Wight, 4 Trowbridge, 5 Braydon, 6 Malvern, 7 Grafton Woods, 8 Bernwood, 9 Western Germany, 10 Western Poland, 11 Aquitaine, 12 Brittany, 13 Catalonia, 14 Lombardy, 15 Umbria. (Color figure online) 

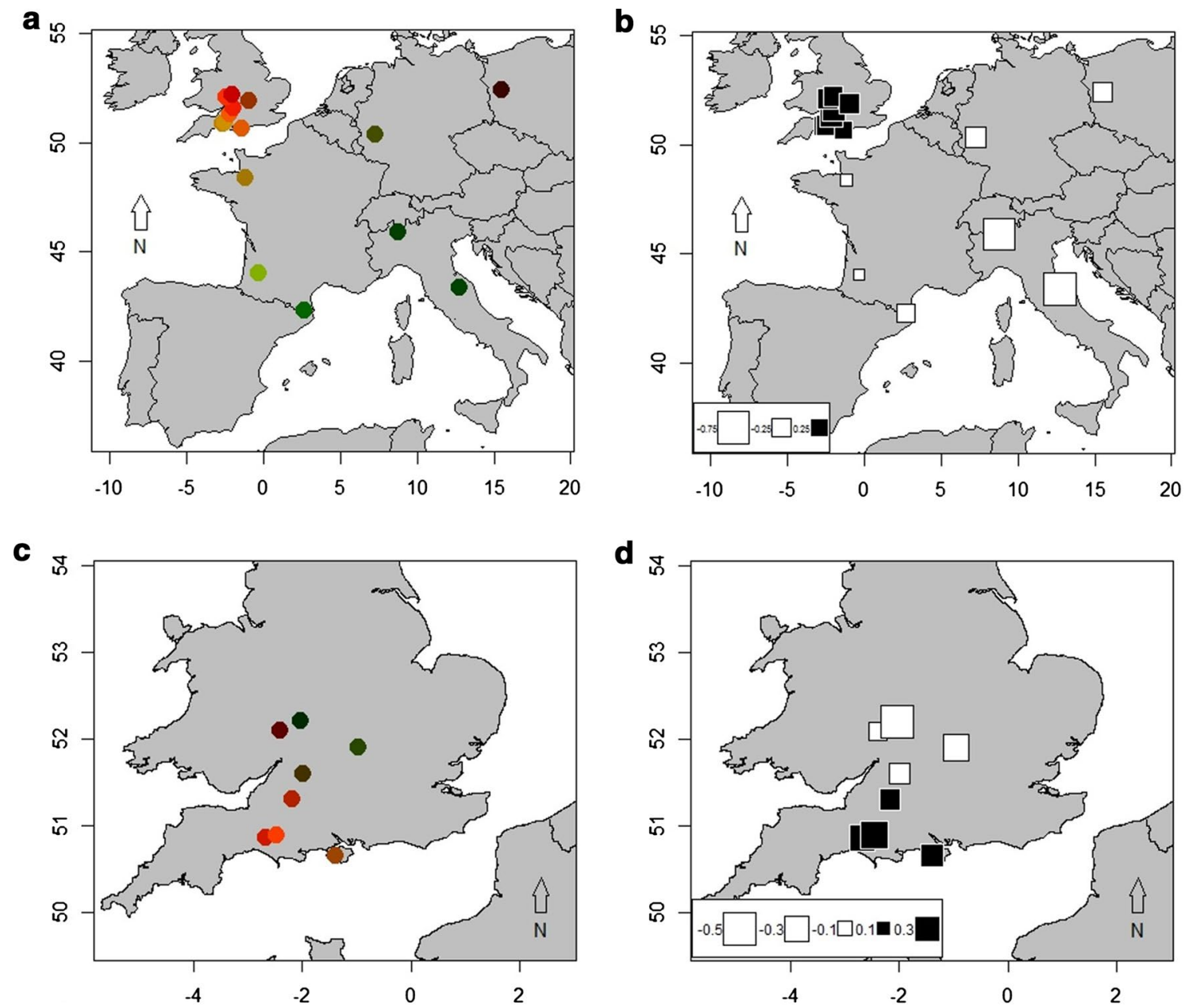

Fig. 4 Analysis of global structure among $M$. bechsteinii in Europe (a, b) and Britain (c, d) by spatial PCA (sPCA) on 14 microsatellite loci. For a, c colours are indicative of the population score for the

first and second principal components. For b, $\mathbf{d}$ square size and colours represent population scores of the first principal component and are positioned according to their location. (Color figure online)

differentiated the British population from the rest of Europe. Both Italian populations also appeared to show signs of isolation from the rest of Europe. The second eigenvector was weaker and showed no clear structure in the dataset. No local structuring was found (Monte-Carlo test, R-squared $=0.02$, $\mathrm{p}=1)$. In Britain, the global test indicated significant structuring (Monte-Carlo test, R-squared $=0.49, \mathrm{p}=0.02$ ) as opposed to the local test which was not significant (MonteCarlo test, $R$-squared $=0.06, p=0.99$ ). Both the representation of the first two eigenvalues (Fig. 4c) and the first eigenvector (Fig. 4d) clearly differentiated the southern populations from the northern populations.

\section{Mitochondrial DNA analysis}

A total of 12 haplotypes were identified among the subset of 183 samples from 15 sites. The mean genetic diversity across Europe was very low $(\mathrm{d}=0.001, \mathrm{SE}=0.001)$ as

most $M$. bechsteinii samples across the species range shared one common haplotype (Fig. 5a). A total of 10 haplotypes observed were comprised of less than 6 individuals and did not differ from the main haplotype by more than 3 bps. Bats from southern Britain (Isle of Wight, Brackett's Coppice and Sherborne) all shared a unique haplotype (Fig. 5b) and the Bechstein's bat sequence from Turkey available on Genbank (KF218378.1) showed the strongest difference with all other haplotypes identified (Fig. 5c).

\section{Discussion}

This study demonstrates significant population structure between continental Europe and Britain. Although genetic diversity is high across the species range, it is nevertheless lower in Britain than elsewhere in Europe. Most of the genetic structure appears to be influenced by geographical 
Fig. 5 Representation of the mtDNA cytochrome b haplotypes for M. bechsteinii. a pie chart representing the haplotype frequencies at each sampling site in Europe and the whole of Britain; b pie chart representing the haplotype frequencies at each sampling site in Britain (colour coding for each haplotype is the same in $\mathbf{a}$ and $\mathbf{b}$ ); $\mathbf{c}$ median joining network. British haplotypes are represented in white, continental Europe in grey and the Turkish haplotype in black. Mutations are represented as hatch marks and the size of each circle reflects the number of individuals for each haplotype. (Color figure online) a

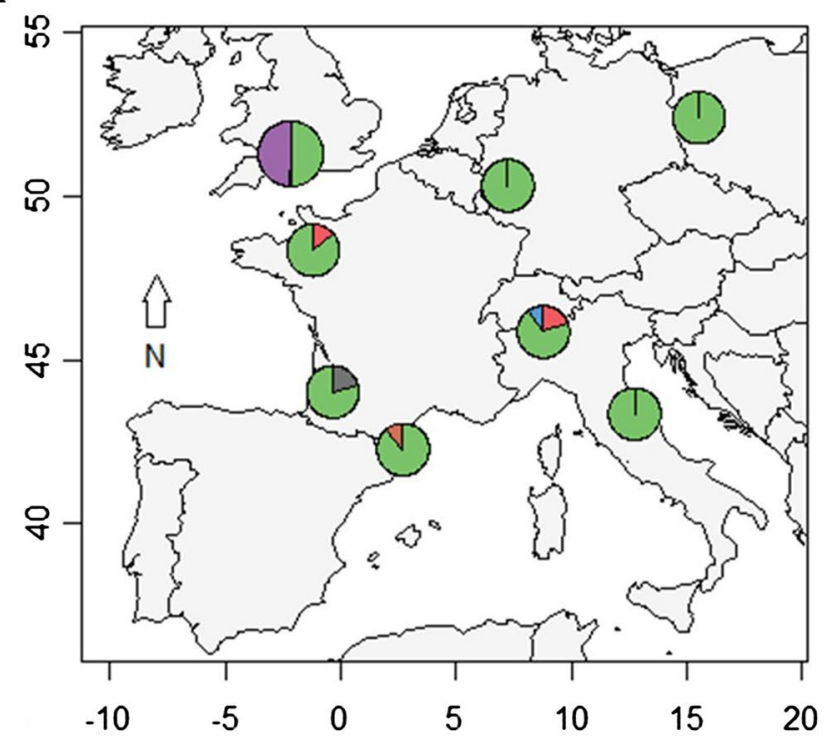

b

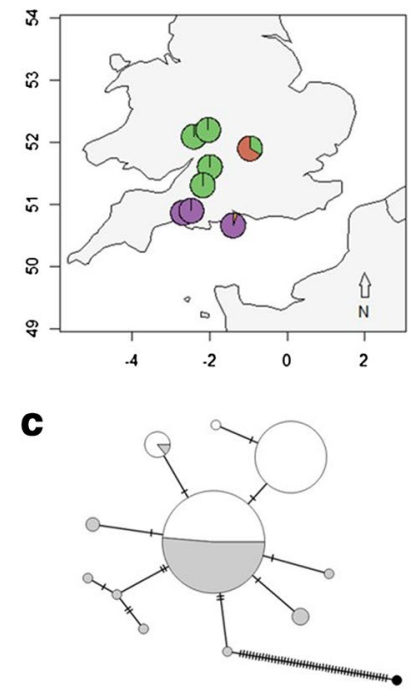

barriers, such as the English Channel and the Alps, but the microsatellite and mtDNA analyses also revealed important genetic structuring between the northern and southern part of the species range in Britain.

\section{Genetic diversity}

Levels of diversity are high, and are similar to more common Myotis species found in Europe, such as M. daubentonii (Smith et al. 2011), M. nattereri (Rivers et al. 2005), M. myotis (Ruedi and Castella 2003), M. mystacinus and M. brandtii (Bogdanowicz et al. 2012). The use of numerous autumn swarming sites throughout their range is likely to play an important role in maintaining high genetic diversity as it is frequently observed behaviour in Myotis bats (Kerth et al. 2003). However, island populations are more susceptible to factors such as genetic drift, and tend to express lower levels of diversity than continental populations (Frankham 1997). Although we observed more genetic diversity than previously reported for this species in Britain (Durrant et al. 2009), these levels remained slightly lower than in Europe. The isolation of the Bernwood populations from other populations may also explain why this population is the only one showing higher levels of inbreeding and less genetic diversity.

\section{Genetic structure}

The STRUCTURE analysis revealed a clear separation between the British and continental populations, which suggests that the English Channel acts as a barrier to gene flow between Britain and mainland Europe. Such differentiation has been observed in a number of bats, such as
Myotis daubentonii (Atterby et al. 2010), Plecotus austriacus (Razgour et al. 2013) and Eptesicus serotinus (Moussy et al. 2015). Bechstein's bats sampled on the Isle of Wight, located off the British coast, did not show any differentiation compared with the rest of Britain (at $\mathrm{K}=2$ ); in contrast to the patterns observed for E. serotinus (Moussy et al. 2015). Although M. bechsteinii forage over much shorter distances than E. serotinus (Catto et al. 1996; Dietz and Pir 2011), it appears that they will more readily cross short distances of open water. Such events may well be infrequent but strongly related with mating and autumn swarming events enabling connectivity between populations.

Large geographical barriers, such as the English Channel and the Alps, explained genetic differentiation between populations in the STRUCTURE analysis. However, these trends were not apparent when analysing isolation by distance (IBD) with the full dataset. IBD often gives biased results by identifying stepping stone trends of IBD for cases of hierarchical structure (Meirmans 2012). To control this bias, we performed Mantel tests on the separate clusters identified by STRUCTURE. In this case, the effect of the Alps was clearly identified as a geographic barrier on the continental dataset despite recording swarming activity above $1500 \mathrm{~m}$ (Petrov 2006). Mountain ranges are also known to be an important geographic barrier and to have a significant effect on the genetic structure of M. myotis (Ruedi et al. 2008) and P. austriacus (Razgour et al. 2013).

As with Durrant et al. (2009), IBD within the British population of $M$. bechsteinii was not detected in our study. However, results from STRUCTURE and SPCA emphasised a clear separation between the southern and northern part of the species national distribution. The absence of obvious physical barriers such as mountain ranges between both 
populations suggests that anthropogenic barriers, such as differences in land-use, may explain the differentiation.

\section{Mitochondrial DNA analysis and genetic history}

The cytochrome $\mathrm{b}$ gene is known as a good indicator of mitochondrial diversity for mammals (Combe et al. 2016; Stojak et al. 2016) and other vertebrates (Zhu et al. 2014). However, several European bat species show very little mitochondrial divergence throughout their range as observed with M. bechsteinii (Çoraman et al. 2013; Ibáñez et al. 2006; Rebelo et al. 2012; Salgueiro et al. 2007). Although most British populations shared the same haplotype as continental bats, the southern populations had a unique haplotype that differed by a single base pair from the rest of Europe and Britain. Such differentiation agrees with results from the nuclear microsatellite data and similar differentiation has also been observed in E. serotinus (Moussy et al. 2015). In the absence of clear physical barriers, the break observed may be linked to a lack of essential habitat, such as woodlands and potential swarming sites, which can limit the dispersal abilities of $M$. bechsteinii and further explain the separation between both populations.

Our finding of little diversity across the whole of Europe confirms a recent population range expansion which coincides with post-glacial colonisation as observed in multiple bat species (Moussy et al. 2015; Petit et al. 1999; van Schaik et al. 2017). Kerth et al. (2008) analysed the HV2 and ND1 mitochondrial genes of $M$. bechsteinii from the Balkans and suggested that this population may have been the unique glacial refugium for the species as genetic diversity was higher than in Europe. Glacial refugia are prone to higher levels of genetic diversity than recently colonised areas. Multiple continental clusters have been identified for E. serotinus, $M$. myotis, R. ferrumequinum or B. barbastellus indicating the recolonization of Europe from separate refugia (Moussy et al. 2015; Rebelo et al. 2012; Rossiter et al. 2000; Ruedi et al. 2008). Although our study lacks samples from the Balkans, it confirms that Italy and Spain were unlikely ancient glacial refugia for the species as they mainly share the same haplotype as the rest of Europe (Kerth et al. 2008). The Balkans has also been identified as an important refugium for $N$. noctula (Petit et al. 1999). This species differs from $M$. bechsteinii as it is known to be migratory and will disperse more than $400 \mathrm{~km}$. However, both species highly depend on woodland and tree cavities for roosting as opposed to E. serotinus, $M$. myotis, $R$. ferrumequinum. Fagus sylvatica (beech) has also undergone an important post-glacial range expansion from a main source population in the Balkans (Magri 2008; Magri et al. 2006). As discussed by Kerth et al. (2008), the increased presence of beech woodlands may have been the main driver behind the post-glacial range expansion of M. bechsteinii and $N$. noctula by providing them with suitable habitat and roosting opportunities as both species share strong similarities in range and phylogeographic history.

\section{Conservation implications}

Bats often show less genetic differentiation than terrestrial mammals (Ibáñez et al. 2006). However, habitat fragmentation can significantly increase isolation of more sedentary bat species and lead to genetic drift and inbreeding (Meyer et al. 2009). M. bechsteinii shows high levels of genetic diversity and little differentiation throughout Europe. However, the British population appears to be showing less diversity and more genetic structure over a smaller area than on the continent in the absence of obvious physical barriers. Founder effects may explain the lower levels of diversity, but the presence of clear population structure could be the result of anthropogenic factors. The effective dispersal mechanisms of $M$. bechsteinii and genetic exchange at swarming sites may have limited the impact of these threats to date, but continued pressures on landscape connectivity means that long-term monitoring is essential.

The identification of a population showing signs of inbreeding and low genetic diversity is of concern. This is particularly relevant to populations on the extreme edges of the British range for instance the Bernwood population, in Buckinghamshire. Such populations are likely to be more sensitive to the continual expansion of built developments and other threats that cause habitat fragmentation and loss.

In conclusion, we observed high levels of diversity across Britain and Europe, although diversity was lower in Britain. Geographic barriers, such as the English Channel and the Alps, explain most of the genetic structure in our dataset. In Britain, we observed important structuring at a nuclear and mitochondrial level between northern and southern populations which may be influenced by a lack of habitat. The dispersal abilities and slow reproductive rate of $M$. bechsteinii may result in a delayed response in genetic diversity and structure to recent changes in their environment (e.g. habitat loss). It is therefore imperative to regularly monitor the effect of potential threats on populations as isolated populations have shown evidence of lower levels of genetic diversity.

Acknowledgements This project was supported by the Vincent Wildlife Trust, the People's Trust for Endangered Species, the Woodland Trust and the University of Exeter. We thank Keith Cohen, Gareth Harris, Nick Tomlinson, Adrian Bayley, Daniel Whitby, Johnny Birks, Lis Weidt and Colin Morris for helping with the collection of samples in Britain. We also thank Tomasz Kokurewicz, Camille Jan, John Altringham, Andreas Kiefer, Eric Petit, Arnaud le Houédec, Yann le Bris, Martina Spada, Dino Scaravelli, Xavier Puig-Montserrat, Carles Flaquer, the Bretagne Vivante team and members of the groupe Chiroptère Aquitaine for contributing towards the collection of European 
samples. We are grateful for the input, help and assistance of local bat groups, local Wildlife Trusts and home owners. We also thank Laura Kubasiewicz for constructive comments, which greatly improved the manuscript.

Data accessibility The mitochondrial sequence data is available on GenBank (MF182931- MF183112) and microsatellite genotypes for $M$. bechsteinii are available upon request.

\section{Compliance with ethical standards}

Conflict of interest The authors declares no conflict of interest.

Open Access This article is distributed under the terms of the Creative Commons Attribution 4.0 International License (http://creativeco mmons.org/licenses/by/4.0/), which permits unrestricted use, distribution, and reproduction in any medium, provided you give appropriate credit to the original author(s) and the source, provide a link to the Creative Commons license, and indicate if changes were made.

\section{References}

Ahlén I, Baagøe HJ, Bach L (2009) Behavior of Scandinavian bats during migration and foraging at sea. J Mammal 90(6): 1318-1323

Atterby H, Aegerter JN, Smith GC, Conyers CM, Allnutt TR, Ruedi $\mathrm{M}$ et al (2010) Population genetic structure of the Daubenton's bat (Myotis daubentonii) in western Europe and the associated occurrence of rabies. Eur J Wildl Res 56(1):67-81

Baker PJ, Harris S (2007) Urban mammals: what does the future hold? An analysis of the factors affecting patterns of use of residential gardens in Great Britain. Mammal Rev 37(4):297-315

Bogdanowicz W, Piksa K, Tereba A (2012) Genetic structure in three species of whiskered bats (genus Myotis) during swarming. J Mammal 93(3):799-807

Bryja J, Kaňuch P, Fornůsková A, Bartonička T, Řehák Z (2009) Low population genetic structuring of two cryptic bat species suggests their migratory behaviour in continental Europe. Biol J Lin Soc 96(1):103-114

Catto CMC, Hutson AM, Racey PA, Stephenson PJ (1996) Foraging behaviour and habitat use of the serotine bat (Eptesicus serotinus) in southern England. J Zool 238:623-633

Combe FJ, Ellis JS, Lloyd KL, Cain B, Wheater CP, Harris WE (2016) After the ice age: the impact of post-glacial dispersal on the phylogeography of a small mammal, Muscardinus avellanarius. Front Ecol Evol 4:1-12

Çoraman E, Furman A, Karataş A, Bilgin R (2013) Phylogeographic analysis of Anatolian bats highlights the importance of the region for preserving the Chiropteran mitochondrial genetic diversity in the Western Palaearctic. Conserv Genet 14(6):1205-1216

Couzens D, Swash A, Still R, Dunn J (2017). Britain's mammals: a field guide to the mammals of Britain and Ireland. Princeton University Press, Princeton

Dekeukeleire D, Janssen R, Haarsma A-J, Bosch T, Schaik JV (2016) Swarming behaviour, catchment area and seasonal movement patterns of the Bechstein's bats: implications for conservation. Acta Chiropterologica 18(2):349-358

Dietz M, Pir JB (2011). Distribution, ecology and habitat selection by bechstein's bat (Myotis Bechsteinii) in Luxembourg. Laurenti

Durrant CJ, Beebee TJ, Greenaway F, Hill DA (2009) Evidence of recent population bottlenecks and inbreeding in British populations of Bechstein's bat, Myotis bechsteinii. Conserv Genet 10(2):489-496

Ellis J, Knight ME, Darvill B, Goulson D (2006) Extremely low effective population sizes, genetic structuring and reduced genetic diversity in a threatened bumblebee species, Bombus sylvarum (Hymenoptera: Apidae). Mol Ecol 15(14):4375-4386

Evanno G, Regnaut S, Goudet J (2005) Detecting the number of clusters of individuals using the software STRUCTURE: a simulation study. Mol Ecol 14(8):2611-2620

Frankham R (1997) Do island populations have less genetic variation than mainland populations? Heredity 78(3):311-327

Glover AM, Altringham JD (2008) Cave selection and use by swarming bat species. Biol Cons 141(6):1493-1504

Ibáñez C, García-Mudarra JL, Ruedi M, Stadelmann B, Juste J (2006) The Iberian contribution to cryptic diversity in European bats. Acta Chiropterologica 8(2):277-297

Jombart T (2008) Adegenet: a R package for the multivariate analysis of genetic markers. Bioinformatics 24(11):1403-1405

Kalinowski ST (2005) Hp-rare 1.0: a computer program for performing rarefaction on measures of allelic richness. Mol Ecol Notes 5(1):187-189

Kerth G, Mayer F, König B (2000) Mitochondrial DNA (mtDNA) reveals that female Bechstein's bats live in closed societies. Mol Ecol 9(6):793-800

Kerth G, Kiefer A, Trappmann C, Weishaar M (2003) High gene diversity at swarming sites suggest hot spots for gene flow in the endangered Bechstein's bat. Conserv Genet 4(4):491-499

Kerth G, Petrov B, Conti A, Anastasov D, Weishaar M, Gazaryan S et al (2008) Communally breeding Bechstein's bats have a stable social system that is independent from the postglacial history and location of the populations. Mol Ecol 17(10):2368-2381

Leigh JW, Bryant D (2015) Popart: full-feature software for haplotype network construction. Methods Ecol Evol 6(9):1110-1116

Magri D (2008) Patterns of post-glacial spread and the extent of glacial refugia of European beech (Fagus sylvatica). J Biogeogr 35(3):450-463

Magri D, Vendramin GG, Comps B, Dupanloup I, Geburek T, Gömöry D et al (2006) A new scenario for the Quaternary history of European beech populations: palaeobotanical evidence and genetic consequences. New Phytol 171(1):199-221

Marzluff JM (2001). Worldwide urbanization and its effects on birds Avian ecology and conservation in an urbanizing world. Springer, New York, pp 19-47

McDevitt AD, Edwards CJ, O'Toole P, O'Sullivan P, O'Reilly C, Carden RF (2009) Genetic structure of, and hybridisation between, red (Cervus elaphus) and sika (Cervus nippon) deer in Ireland. Mammal Biol Zeitschrift für Säugetierkunde 74(4):263-273

Meirmans PG (2012) The trouble with isolation by distance. Mol Ecol 21(12):2839-2846

Meyer CF, Kalko EK, Kerth G (2009) Small-scale fragmentation effects on local genetic diversity in two Phyllostomid bats with different dispersal abilities in Panama. Biotropica 41(1):95-102

Moussy C, Hosken D, Mathews F, Smith G, Aegerter J, Bearhop S (2013) Migration and dispersal patterns of bats and their influence on genetic structure. Mammal Rev 43(3):183-195

Moussy C, Atterby H, Griffiths A, Allnutt T, Mathews F, Smith G et al (2015) Population genetic structure of serotine bats (Eptesicus serotinus) across Europe and implications for the potential spread of bat rabies (European bat lyssavirus EBLV-1). Heredity 115(1):83-92

O'Shea TJ, Bogan MA (2003). Monitoring trends in bat populations of the United States and territories: problems and prospects. Publications of the US Geological Survey, p 16

Parsons K, Jones G (2003) Dispersion and habitat use by Myotis daubentonii and Myotis nattereri during the swarming season: implications for conservation. Anim Conserv 6(04):283-290 
Paunović M (2016). Myotis bechsteinii. The IUCN Red List of Threatened Species 2016:e.T14123A22053752

Peakall R, Smouse P (2012) GenAlEx 6.5: genetic analysis in Excel. Population genetic software for teaching and research - an update. Bioinformatics 28:2537-2539

Petit E, Excoffier L, Mayer F (1999) No evidence of bottleneck in the postglacial recolonization of Europe by the noctule bat (Nyctalus noctula). Evolution 53(4):1247-1258

Petrov BP (2006) Distribution and status of Myotis bechsteinii in Bulgaria (Chiroptera: Vespertilionidae). Lynx 37:179-195

Potts SG, Biesmeijer JC, Kremen C, Neumann P, Schweiger O, Kunin WE (2010) Global pollinator declines: trends, impacts and drivers. Trends Ecol Evol 25(6):345-353

Pritchard JK, Stephens M, Donnelly P (2000) Inference of population structure using multilocus genotype data. Genetics 155(2):945-959

Puechmaille SJ, Mathy G, Petit EJ (2007) Good DNA from bat droppings. Acta Chiropterologica 9(1):269-276

Razgour O, Juste J, Ibáñez C, Kiefer A, Rebelo H, Puechmaille SJ et al (2013) The shaping of genetic variation in edge-of-range populations under past and future climate change. Ecol Lett 16(10):1258-1266

Razgour O, Taggart JB, Manel S, Juste J, Ibáñez C, Rebelo H et al (2017). An integrated framework to identify wildlife populations under threat from climate change. Mol Ecol Resour 2017:1-14

Rebelo H, Tarroso P, Jones G (2010) Predicted impact of climate change on European bats in relation to their biogeographic patterns. Glob Change Biol 16(2):561-576

Rebelo H, Froufe E, Brito JC, Russo D, Cistrone L, Ferrand N et al (2012) Postglacial colonization of Europe by the barbastelle bat: agreement between molecular data and past predictive modelling. Mol Ecol 21(11):2761-2774

Reed DH, Frankham R (2003) Correlation between fitness and genetic diversity. Conserv Biol 17(1):230-237

Rice W (1989) The sequential Bonferroni test. Evolution 43:223-225

Rivers NM, Butlin RK, Altringham JD (2005) Genetic population structure of Natterer's bats explained by mating at swarming sites and philopatry. Mol Ecol 14(14):4299-4312

Rossiter SJ, Jones G, Ransome RD, Barratt EM (2000) Genetic variation and population structure in the endangered greater horseshoe bat Rhinolophus ferrumequinum. Mol Ecol 9(8):1131-1135

Rousset F (2008) Genepop'007: a complete re-implementation of the genepop software for Windows and Linux. Mol Ecol Resour 8(1):103-106

Ruedi M, Castella V (2003) Genetic consequences of the ice ages on nurseries of the bat Myotis myotis: a mitochondrial and nuclear survey. Mol Ecol 12(6):1527-1540
Ruedi M, Walter S, Fischer MC, Scaravelli D, Excoffier L, Heckel G (2008) Italy as a major ice age refuge area for the bat Myotis myotis (Chiroptera: Vespertilionidae) in Europe. Mol Ecol 17(7):1801-1814

Salgueiro P, Ruedi M, Coelho M, Palmeirim J (2007) Genetic divergence and phylogeography in the genus Nyctalus (Mammalia, Chiroptera): implications for population history of the insular bat Nyctalus azoreum. Genetica 130(2):169-181

Smith MF, Patton JL (1993) The diversification of South American murid rodents: evidence from mitochondrial DNA sequence data for the akodontine tribe. Biol J Lin Soc 50(3):149-177

Smith G, Aegerter J, Allnutt T, MacNicoll A, Learmount J, Hutson A et al (2011) Bat population genetics and Lyssavirus presence in Great Britain. Epidemiol Infect 139(10):1463-1469

Stanton D, Hobbs G, Chadwick EA, Slater FM, Bruford MW (2009) Mitochondrial genetic diversity and structure of the European otter (Lutra lutra) in Britain. Conserv Genet 10(3):733-737

Stojak J, McDevitt AD, Herman JS, Kryštufek B, Uhlíková J, Purger JJ et al (2016) Between the Balkans and the Baltic: phylogeography of a common vole mitochondrial DNA lineage limited to Central Europe. PLoS ONE 11(12):e0168621

Tamura K, Dudley J, Nei M, Kumar S (2007) MEGA4: molecular evolutionary genetics analysis (MEGA) software version 4.0. Mol Biol Evol 24(8):1596-1599

Van Oosterhout C, Hutchinson WF, Wills DP, Shipley P (2004) MICRO-CHECKER: software for identifying and correcting genotyping errors in microsatellite data. Mol Ecol Notes 4(3):535-538

van Schaik J, Dekeukeleire D, Gazaryan S, Natradze I, Kerth G (2017). Comparative phylogeography of a vulnerable bat and its ectoparasite reveals dispersal of a non-mobile parasite among distinct evolutionarily significant units of the host. Conserv Genet 2017:1-14

Vergari S, Dondini G, Ruggieri A (1998). On the distribution of Myotis bechsteinii (Kuhl, 1817) in Italy (Chiroptera: Vespertilionidae). Hystrix Italian J Mammal 10(2)

Yalden D (1992) Changing distribution and status of small mammals in Britain. Mammal Rev 22(2):97-106

Yalden D (1999). The history of British mammals. A\&C Black, London

Zhu Y, Cheng Q, Rogers SM (2014). Genetic structure of Scomber japonicus (Perciformes: Scombridae) along the coast of China revealed by complete mitochondrial cytochrome b sequences. Mitochondr DNA 2014:1-9 